\title{
WET-ETCH FIGURING Optical by Controlled Application of Liquid Etchant
}

\author{
J. Britten
}

February 13, 2001

\section{U.S. Department of Energy}

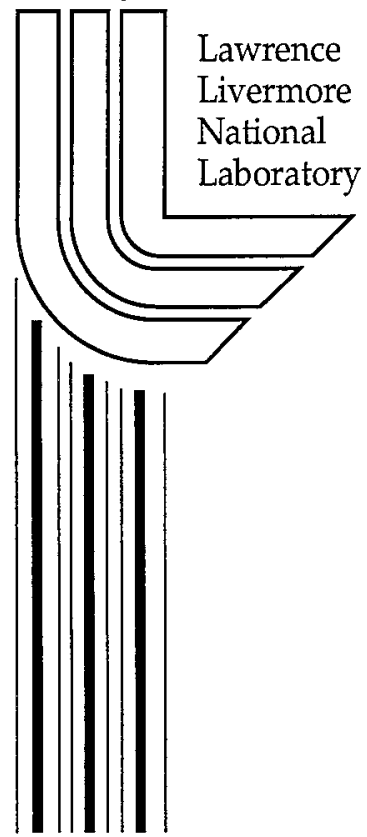




\section{DISCLAIMER}

This document was prepared as an account of work sponsored by an agency of the United States Government. Neither the United States Government nor the University of California nor any of their employees, makes any warranty, express or implied, or assumes any legal liability or responsibility for the accuracy, completeness, or usefulness of any information, apparatus, product, or process disclosed, or represents that its use would not infringe privately owned rights. Reference herein to any specific commercial product, process, or service by trade name, trademark, manufacturer, or otherwise, does not necessarily constitute or imply its endorsement, recommendation, or favoring by the United States Government or the University of California. The views and opinions of authors expressed herein do not necessarily state or reflect those of the United States Government or the University of California, and shall not be used for advertising or product endorsement purposes.

This work was performed under the auspices of the U. S. Department of Energy by the University of California, Lawrence Livermore National Laboratory under Contract No. W-7405-Eng-48.

This report has been reproduced directly from the best available copy.

Available electronically at http://www.doc.gov/bridge

Available for a processing fee to U.S. Department of Energy

And its contractors in paper from

U.S. Department of Energy

Office of Scientific and Technical Information

P.O. Box 62

Oak Ridge, TN 37831-0062

Telephone: (865) 576-8401

Facsimile: (865) 576-5728

E-mail: reports@adonis.osti.gov

Available for the sale to the public from

U.S. Department of Commerce

National Technical Information Service

5285 Port Royal Road

Springfield, VA 22161

Telephone: (800) 553-6847

Facsimile: (703) 605-6900

E-mail: orders@ntis.fedworld.gov

Online ordering: http://www.ntis.gov/ordering.htm

OR

Lawrence Livermore National Laboratory

Technical Information Department's Digital Library

http:/ / www.llnl.gov/tid/Library.html 


\section{WET-ETCH FIGURING \\ Optical Figuring by Controlled Ipplication of Liquid Etchant}

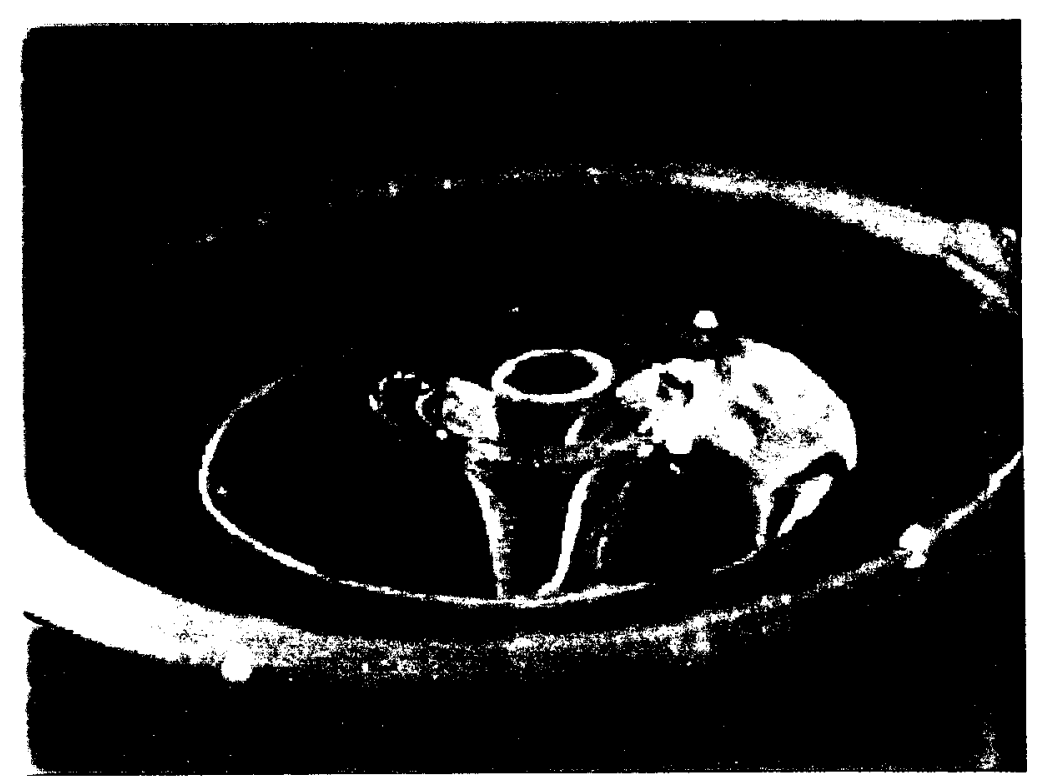

WET-ETCH FIGURING (WEF) is a fully automated optical figuring method that uses a surface-tension-gradient-driven flow of an aqueous processing solution to precisely figure optical surfaces without applying stress to the optical material. Because it is stress-free, WEF is particularly suitable for figuring extremely thin glass sheets, and permits real time monitoring and control of the figuring process interferometrically - allowing for robust, truly deterministic optical figuring without the iterative polish-measure cycle of more traditional figuring methods. 


\section{Submitting organization:}

$\begin{array}{ll}\text { Organization: } & \text { Lawrence Livermore National Laboratory (LLNL) } \\ \text { Address: } & \text { 7000 East Avenue, P.O. Box } 808 \\ \text { City: } & \text { Livermore } \\ \text { State: } & \text { California } \\ \text { ZIP: } & 94550 \\ \text { Country: } & \text { USA } \\ \text { Submitter's name: } & \text { Jerald A. Britten } \\ \text { Phone: } & \text { (925) 423-7653 } \\ \text { Fax: } & \text { (925) 422-5537 } \\ \text { E-mail } & \text { brittenl@llnl.gov }\end{array}$

AFFIRMATION: I affirm that all information submitted as a part of, or supplemental to, this entry is a fair and accurate representation of this product.

Submitter's signature:

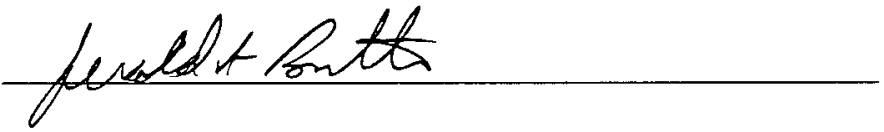

\section{Joint entry: No}

\section{Product Name:}

WET-ETCH FIGURING--Optical Figuring by Controlled Application of Liquid

\section{Brief description of entry:}

WET-ETCH FIGURING (WEF) is an automated method of precisely figuring optical materials by the controlled application of aqueous etchant solution. This technology uses surface-tension-gradient-driven flow to confine and stabilize a wetted zone of an etchant solution or other aqueous processing fluid on the surface of an object. This wetted zone can be translated on the surface in a computer-controlled fashion for precise spatial control of the surface reactions occurring (e.g. chemical etching). WEF is particularly suitable for figuring very thin optical materials because it applies no thermal or mechanical stress to the material. Also, because the process is stress-free the workpiece can be monitored during figuring using interferometric metrology, and the measurements obtained can be used to control the figuring process in real-time - something that cannot be done with traditional figuring methods.

\section{When was this product first marketed or available for order:}

This process first became available for license in December of 2000. 
6. Inventor or Principal Developer:

$\begin{array}{lllll}\text { Developers: } & \text { M. C. Rushford } & \text { J. A. Britten } & \text { L. J. Summers } & \text { C. R. Hoaglan } \\ \text { Position: } & \text { Physicist } & \text { Chem. Engineer } & \text { Chemist } & \text { Technician } \\ \text { Phone: } & \text { (925) 424-6349 } & \text { (925) 423-7653 } & (925) 422-8027 & (925) 423-3765 \\ \text { E-mail: } & \text { rushford1@llnl.gov britten1@llnl.gov summers3@lln1.,gov } & \text { hoaglan1@llnl.gov } \\ \text { Organization: } & \text { Lawrence Livermore National Laboratory (LLNL) } & \\ \text { Address: } & \text { 7000 East Ave. P.O. Box 808 } & \\ \text { City: } & \text { Livermore } & & \\ \text { State: } & \text { California } & & \\ \text { ZIP: } & 94550 & & \\ \text { Country: } & \text { USA } & & \end{array}$

\section{Product price}

The licensing price for this technology is being negotiated.

\section{Do you hold any patents or patents pending on this process? Yes[X] No [ ]}

\section{Product description:}

What does it do? WET-ETCH FIGURING is an entirely new process for figuring complex optical surfaces. It confines an aqueous etching solution to a stable footprint of a controllable size on the surface of the optical material being figured. As the confined etchant is moved over the surface of the material, etching or dissolution of the surface occurs. Unlike other figuring techniques, WEF is stress-free; that is, the workpiece experiences no mechanical or thermal stress during processing. Thus, an interferometer can be used to measure the material while it is being figured, and these measurements can be used to control where the etching solution is applied to the material and how long it stays there-all without interrupting the process. The lack of stress also means that WEF is perfect for figuring very thin (less than 1 millimeter thick) optic glasses to precise optical tolerances, something achievable only at great expense using other methods.

How does it work? WEF is simple to implement, operates at ambient conditions, and requires no elaborate or expensive tooling. It makes use of the principles of interfacial transport phenomena, optical interferometry, and machine control in an integrated process for feedback-controlled optical figuring using wet chemical etching. WEF employs a surface-tension-gradient-induced flow (the Marangoni effect) to confine the aqueous etching solution on the surface of the material being etched. Surface-tension gradients can be thermally or chemically-induced; we use chemistry to provide the effect. (See Figure 1 and the accompanying video for an explanation.) Briefly, an aqueous etching solution flowing up through and then down the outside of a tube wets the underside surface of an optical material when this surface is placed very close to the tube end. Since the fluid wets the surface, a drop forms, and the bottom of the drop transitions into a film flowing down the outside of the tube. This is illustrated in the cover photo.

Normally, when the etchant drop is moved laterally along the surface, a thin film of etchant is left behind, that continues to work on the surface. If, however, a water-soluble 
volatile organic compound (VOC) (e.g., low-molecular-weight alcohol vapor) is introduced in the vacinity of the tube either by evaporation from a pool or convection in a carrier gas, the vapor absorbs into the etchant, building to a somewhat higher concentration in the relatively quiet zone near the material's surface than in the continuously refreshed falling film zone. Minute concentrations of absorbed VOC's have a profound effect on the surface tension of the aqueous etchant. The concentration gradient of VOC's in the vicinity of the attached drop gives rise to a surface-tension gradient strong enough to pull the liquid film of etchant off of the material's surface and confine it in a stable pattern. The confined etchant can now be moved across the surface of the optical material without leaving behind a film or changing shape. Thus, the size and shape of the zone being etched at any given time is constant and controlled, and optical figuring becomes possible.

No thermal or mechanical stresses are applied to the optical material during this process. Because the entire top surface of the material can be unsupported and free of obstruction, an optical interferometer can be set up to look down through the workpiece from the top and measure its optical thickness, either globally or at a spot coincident with the center of the wetted zone. The measurements are made in real time while the surface is being etched, and this information can be used to control the speed and movement of the wetted zone of etchant. Thus, time-consuming iterative polish/measure cycles are eliminated. The process is robust with respect to changes in ambient conditions as well since it does not rely on precise knowledge of surface removal rates, but rather measures them in real time.

\section{0a. Competitive products:}

Currently, the field of optical figuring is dominated by techniques using abrasive polishing tools. Many companies (e.g., Zygo, SVG-Tinsley, United Lens Inc.) employ small-tool abrasive finishing (STF) for figuring aspheric lenses, continuous contour phase plates, and other complex optical surfaces. Recently, QED Technologies and Zygo Inc. commercialized a magneto-rheological finishing (MRF) technology, which uses small tools. This process is a variant of traditional polishing. It allows for fine lateral feature control and faster removal rates by controlling the viscosity of a ferromagnetic abrasive slurry by application of external magnetic fields. In general, these abrasive polishing techniques rely on precise knowledge of material removal rates, because the surface figure is not measured during the process. The workpiece must be removed from the figuring machine and return to room temperature before surface figure is measured with a separate instrument. Thin substrates (a few millimeters or less thick) are also difficult to figure using abrasive polishing techniques because the pressure of the tool can deform the workpiece, altering surface removal rates. Polishing processes in general also leave behind a gel layer that can be a few micrometers thick. It consists mostly of hydrated glassy material redeposited from the polishing process, and can also contain very small grains of abrasive material. In fact, it is this gel material that results in a very smooth optical surface. However, the presence of the abrasive particles in the gel layer negatively affects optics employed in high-power ultraviolet transmission systems by absorbing the radiation that can seed optically induced damage to the surface.

Ion-beam figuring (IBF) is also used to figure complex surfaces on optical substrates. IBF has commercialized by Kodak Inc., mainly for large telescope and space-based optical elements. This process removes surface material by moving an ion beam over the surface of 
the substrate, causing sputtering of the surface material. This process also requires precise knowledge of material removal rates because no measurements are be made of the material during figuring. Also, because the ion beam that is key to this process must operate in a large high-vacuum chamber requiring elaborate pumping equipment and high-voltage electronics, IBF apparatus is expensive to build and operate.

Finally, plasma-assisted chemical etching (PACE) has also been developed to some extent. This process suffers from the same disadvantages as IBF. The processing equipment is expensive to build and operate, and the workpiece cannot be measured while the figuring process in under way.

10b. Comparison matrix:

\begin{tabular}{|l|c|c|c|c|c|}
\hline \multicolumn{1}{|c|}{ Technique } & WEF & STF & MRF & IBF & PACE \\
\hline Workpiece can be measured during processing & $\mathbf{X}$ & & & & \\
\hline Ambient process & $\mathbf{X}$ & $\mathrm{X}$ & $\mathrm{X}$ & & \\
\hline Stress-free figuring of workpiece & $\mathbf{X}$ & & & $*$ & $*$ \\
\hline Can easily figure material less than a millimeter thick & $\mathbf{X}$ & & & $\mathrm{X}$ & $\mathrm{X}$ \\
\hline $\begin{array}{l}\text { Automated, totally deterministic finishing with real- } \\
\text { time metrology }\end{array}$ & $\mathbf{X}$ & & & & \\
\hline Can smooth optically rough surfaces & & $\mathrm{X}^{+}$ & $\mathrm{X}^{+}$ & & \\
\hline
\end{tabular}

$1 \mathrm{WEF}=$ WET-ETCH FIGURING; STF = small-tool finishing; MRF = magneto-rheological finishing; IBF = ionbeam figuring; $P A C E=$ plasma-assisted chemical etching.

* Can induce thermal gradients.

+ However, mechanical contact by tool can lead to scratch/dig damage to surface.

\section{0c. Improvements upon competitive technologies:}

WEF's unique advantages over competing processes are:

- During the fully automated wet-etch figuring process, the workpiece can be measured with an interferometer, and the results of those measurements can be used to control and correct the figuring process.

- WEF takes place at room temperature and pressure and is inexpensive to implement.

- WEF is an enabling technology for precision optical figuring of very thin optics, that now can be utilized in a variety of applications (e.g., flat-panel displays) that were cost-prohibitive to produce previously. 
Wet-etch figuring-cannot create a smoother finish on a fine scale (single micrometers to $10 \mathrm{~s}$ of micrometers) than the finish the optic originally had. In other words, the optic must possess a specular surface (either as is, in the case of extruded or float glass, or as a result of a traditional polishing step) before this technique is used to do final figuring. This fact does not constitute a limitation of the process: all final figuring techniques start with optically smooth surfaces. If the material is heterogeneous on this fine scale or has been polished using a method that has resulted in subsurface scratches, digs, etc. that have been filled in with gel material, WEF will result in a roughened surface.

Livermore researchers have developed WEF circular spot tools for two-dimensional figuring and long, narrow slotted tools for one-dimensional flattening of large thin glass sheets. Figure 2 shows an interferogram of a $150-\times 250-\mathrm{mm}$ section of a 380 -micrometerthick borosilicate glass sheet, originally exhibiting about 10 waves of optical distortion, that was flattened using automated WEF to less than 1 wave of optical distortion. The ability of WEF to create such thin, optically precise glass sheets cost effectively over large areas opens up new possibilities for such glass in lightweight-critical applications such as spacebased optics, astronomy, laser and imaging systems, and other applications where optical distortion is to be minimized.

\section{1b. Principal applications of this technology:}

This new process can be used for:

- Aspheric figuring of lenses.

- Figuring of complex shapes such as continuous contour phase screens diffusers, Alvarez lenses, static wavefront correctors and other optics used in lasers systems, astronomy, precision imaging systems, and lithography.

- Flattening the one-dimensional ripple exhibited by thin commercially extruded submillimeter-thickness glass sheets, making them available cost-effectively for demanding optical applications.

- Figuring lightweight optics for space applications and for astronomical applications, including consumer or hobbyist telescopes.

\section{1b. Other applications for which this technology can now be used:}

This process can be used in any application where local control of the placement of an aqueous processing solution on the surface of a substrate is desired. Such an application exists in the processing of semiconductor wafers (oxide etching or etching of other layers, cleaning, etc.) and in flat-panel-display processing. These opaque or structured surfaces can also be measured with an interferometer by measuring the substrate (or a thin film deposited on the substrate) from below through the transparent etching fluid.

\section{1c. Other potential applications:}

The principles of wet-etch figuring are at their root, generic effects based on a known and proven scientific principle, the Marangoni effect. This technology can be used for drying substrate surfaces following cleaning, for example, or for controlled deposition (as in 
epitaxial growth from aqueous solution) as opposed to the surface removal processes described here.

\section{Why should this product win an R\&D 100 Award?}

WEF is an entirely new process for figuring complex optical surfaces based on different principles than existing optical figuring technologies. Instead of using some means of abrasive polishing to finish optical materials, WEF uses a precisely confined and shaped flow of aqueous etching solution to remove material from the optic's surface. Thus, unlike other finishing processes, WEF is stress-free-that is, the workpiece receives no mechanical or thermal stress while it is being figured.

This lack of stress permits the use of an interferometer to measure the workpiece during the figuring process. These measurements can be used to monitor and control the figuring process according to the exact figuring specifications for the optical material. Processing, measuring, and correcting take place simultaneously, not in a series of expensive, timeconsuming iterative steps. It is also less expensive than some other processes because it operates under ambient conditions and requires no expensive high-vacuum chambers or high-voltage electronics.

The lack of stress also permits figuring of very thin (less than a millimeter thick) lightweight optical materials important in areas as diverse as astronomy and flat panel displays. If competing processes can handle ultrathin material, they can do so only at great expense. 


\section{ORGANIZATIONAL DATA}

13. Chief Executive Officer of submitting company (corporate or university president, government research center director, etc):

$\begin{array}{ll}\text { Name: } & \text { C. Bruce Tarter } \\ \text { Position: } & \text { Director } \\ \text { Organization: } & \text { Lawrence Livermore National Laboratory } \\ \text { Address: } & \text { 7000 East Avenue, P.O. Box 808, L001 } \\ \text { City: } & \text { Livermore } \\ \text { State: } & \text { California } \\ \text { Zip: } & 94551 \\ \text { Country: } & \text { USA } \\ \text { Phone: } & (925) 422-4169 \\ \text { Fax: } & (925) 423-3597 \\ \text { Email: } & \text { tarter1@llnll.gov }\end{array}$

14. Contact person to handle all arrangements on exhibits, banquet, and publicity:

Name: $\quad$ Darlene Horne

Position: Business Partnering Administrator

Organization: Lawrence Livermore National Laboratory (LLNL)

Address: $\quad 7000$ East Avenue, P.O. Box 808, L-795

City: $\quad$ Livermore

State: $\quad$ California

ZIP: $\quad 94550$

Country: USA

Phone: $\quad$ (925) 423-1929

Fax: $\quad$ (925) 423-8988

E-mail_horne1@llnl.gov

15. To whom should reader inquiries about your product be directed?

Name: $\quad$ Jerald A. Britten

Position: Group Leader, Diffractive Optics

Organization: Lawrence Livermore National Laboratory (LLNL)

Address: $\quad 7000$ East Avenue, P.O. Box 808

City: Livermore

State: $\quad$ California

ZIP: $\quad 94550$

Country: USA

Phone: $\quad$ (925) 423-7653

Fax: $\quad$ (925) 422-5537

E-mail_britten1@llnl.gov 
In absence of surface tension gradients, viscous drag of moving substrate applies thin film of water on hydrophilic surface
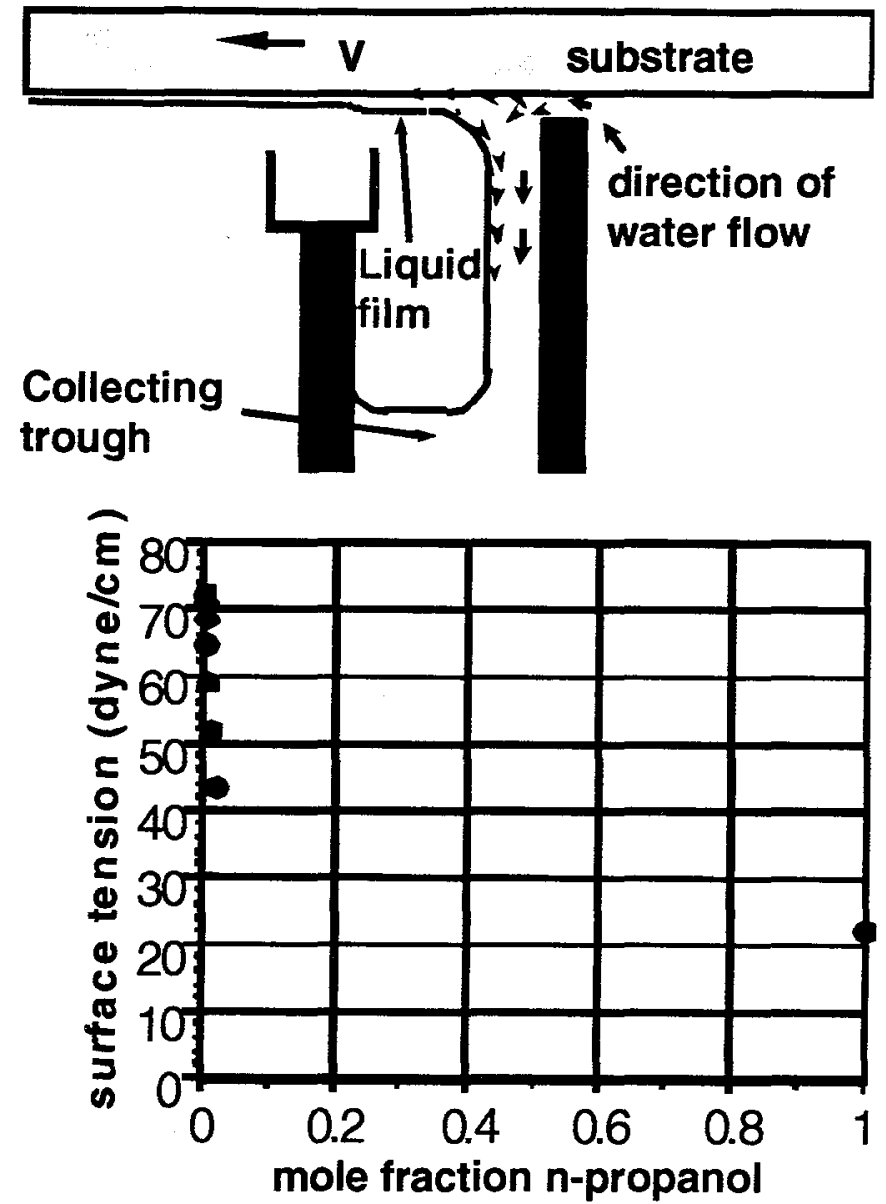

Very small amounts of absorbed alcohol in water have a profound effect on aqueous surface tension

Thin, slow-moving film builds up appreciable amount of absorbed alcohol

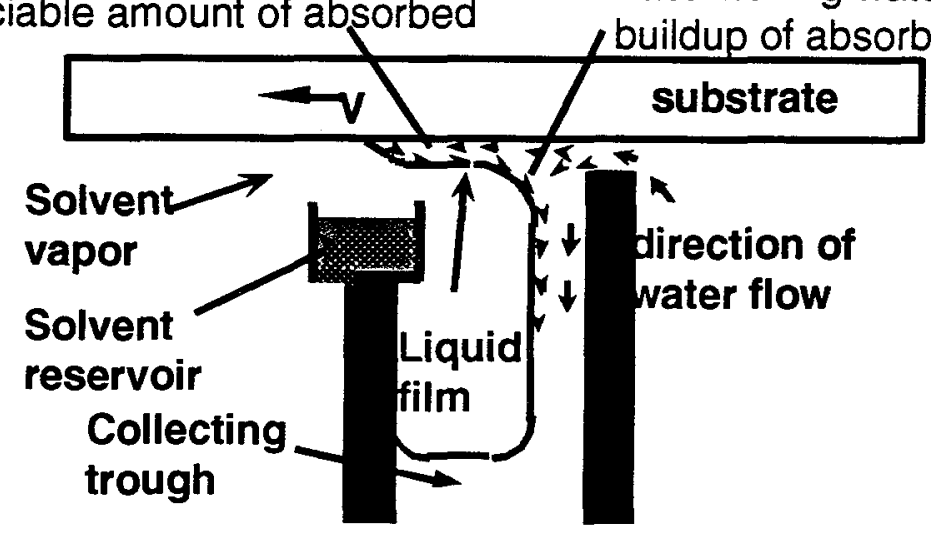

Alcohol-induced surface tension gradient between thin film adhering to substrate and free surface of falling film is sufficiently strong to pull water of of the substrate surface. Wetted zone remains stationary with respect to the applicator.

Figure 1. Pictorial explanation of Marangoni effect applied to wet-etch figuring 

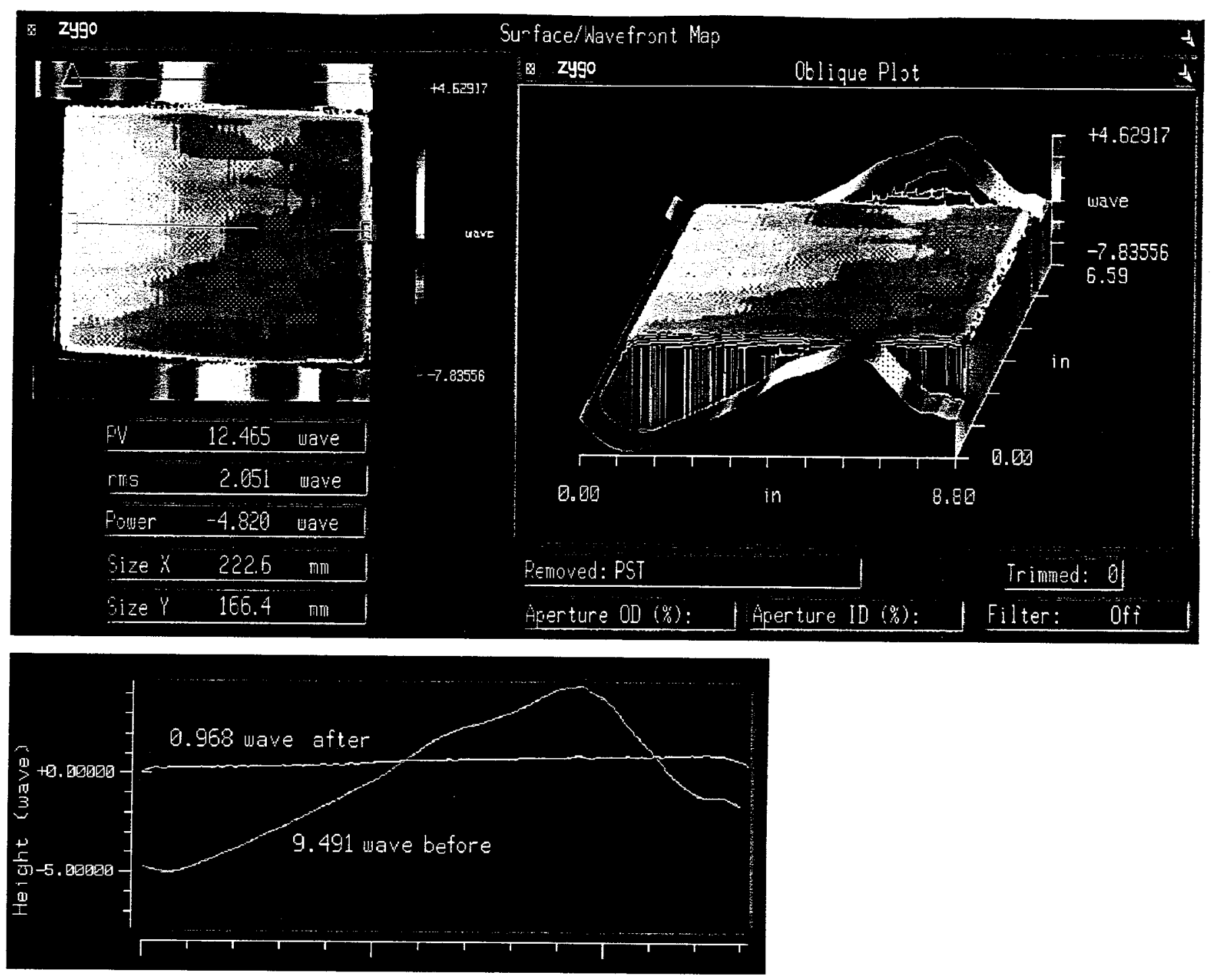

Figure 2. Transmission interferogram of $200 \times 150 \mathrm{~mm}$ section of $400 \mathrm{~mm}$ square, 0.38 $\mathrm{mm}$ thick glass sheet flattened using linear wet-etch figuring. Transmitted wavefront aberration of over 9 waves $(\mathrm{HeNe})$ reduced to less than 1 wave over this area. Over 12 microns of material have been removed at originally thickest section. 
SUPPORTING DOCUMENTS 


\section{R\&D Magarzine \\ 2000 Cleitwater Ave \\ Oak Brook, 116052.3}

Re: R\&D - 100 Award Nomination

\section{Gentlemen:}

Wel etching of substrates is s lundamencal manufacturing step in many high tech industries. It is used in the seminconductor device manufacturing on silieon and GaAs wafers, in the Flat Panel industry, in the Mask making industry, in the hard disk industry and in several other high rech industries such as the inkjet printer head manufacming. In almust any of the above industrits, feature sizes are deceasing and more precision wet processing is necessary. On lop of that, there is a general trend in the industry to change the manufacturing technology from batch based to single substrate based. Lawrence Livermore National Laboratory and in particular 1. A. Britten has develuped a very high precisiun lechnique to apply wet etchants to a horiwontal single substrate that allows lite wet etching to be very accuratc. This technique is very prumising for achieving the high accuracy needed for next gencration manufacturing of smaller feanre sices.

Applied Materials is currently investigating the technology developed and dernonitrated at LLNL for wel etching of single substrates. We belicve this technology will allow very accurate wet elching of single substrates with very low chemical consumplion.

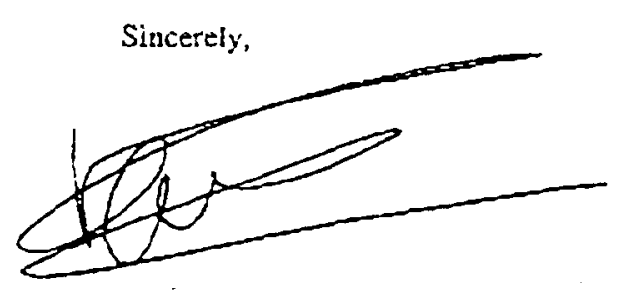

\section{Sicven Verhayerbeke}

Technolugy Manager,

Wet Clean

Applied Materials 
$12^{\text {th }}$ February 2001

To whom it may concern,

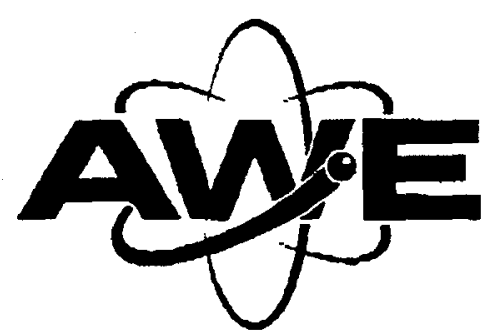

Aldermaston - Reading

Berkshire • RG7 4PR

Tel (0118) 9814111 Fax (0118) 9815320

Subject: Recommendation for Research and Development 100 Award (R\&D 100).

I am writing this letter to recommend the Lawrence Livermore National Laboratory for a 2001 R\&D award for the work emtitled "WET-ETCH OPTICAL IIGURING BY CONTROLLED APPLICATION OF LIQUID ETCHANT ". The innovative work of the wet etch processing team in the development of a wet etch optical polishing tool comes at an appropriate ime to cnable fabrication of the complex surface profiles required on optical components used in high power lasers such as NIF, and HELEN at AWE. Thesc components such as wavefront correction elements and phase plates for modifying far field intensity distributions also bave wide applicability in smaller scale lasers. Indeed, the technique may be applicd in any optical system. The specification of expensive optical components may be relaxed and performance recovered using custom plates manufactorcd by this method, thereby offering significant cost savings in fabricalion.

A beneficiary of this work will be the tera-Watt class HELEN laser at AWE one of only a few such lasers worldwide. This was rebuilt last year to make it the first high power glass laser configured in a multi-pass architecture to be actively deployed as a driver for plasma physios experiments. The wavefront of the laser in this configuration is more sensitive to figure errors in the optics and pump induced phase distortions in the laser amplifiers. One method of improving the wavefront for better focusability is through use of static phase corrector plates. AWE with our research partners, Heriot Wat University, have been investigating the development of these phase plates using dy etch techniques. The reactive ion etch technique requires high fidelity lithographic transfer processes and the etch depth requirement is at the limit of the dry etch process, whereas the new wct etch polishing lool eliminates the lithographic transfer processes and is able to achieve higher etch depths with a better surface finish. The wet etch figuring technique is therefore a significant and timely brcakthrough in fabrication of such optical components.

As Group Leader for Laser Operations and Research at the Atomic Weapons Establishment, AWE, in the UK I am responsible for the operation and furure development of high power solid state laser systems. I have over 26 years experience in the operations and development of high power glass lascrs since joining the establishment, then the Atomic Weapons Research Establishment nun by the UK Ministry of Defence in 1974, following graduation with a BSc Hons in Physics from the University of St. Andrews, Scotland. My particular rescarch interests over the past few years have been on the application of diffractive optical elements which offer great potential in producing components with functionality not realisable by conventional techniques. However, the research indicates that pure difractive components result in porentially damaging intensity modutation on the beam. This new figuring technique may realise the desired functionality without the modulation, a significant breakthrough.

I believe my background qualifies me to make the recommendation of the award for the wet elch figuring technique developed by LLNL. I believe this to be truly outstanding and innovative work, an advancement in optical fabrication and thcrefore well deserving of an R\&D 100 Award.

Sincerely yours

12 उeक

T H Ben

Group Leader, Laser Operations and Rcsearch

TCl $441189825432 \quad$ Fax 441189824842

e-mail tom.bett@awe.co.uk
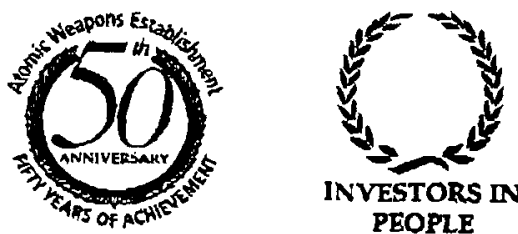
AWE is the trading name of AWE ple
Registered in England and Wales a Regismation ne. 02763902 Registered office: AWE - Aldermation - Reading - RG7 4PR PEOPLE Afy 0 secteary of Stote for Defence 


\section{NIF PROGRAMS AWARD}

\section{Jerald Britten}

Small Tool Wet-etch Optical Figuring Process Team
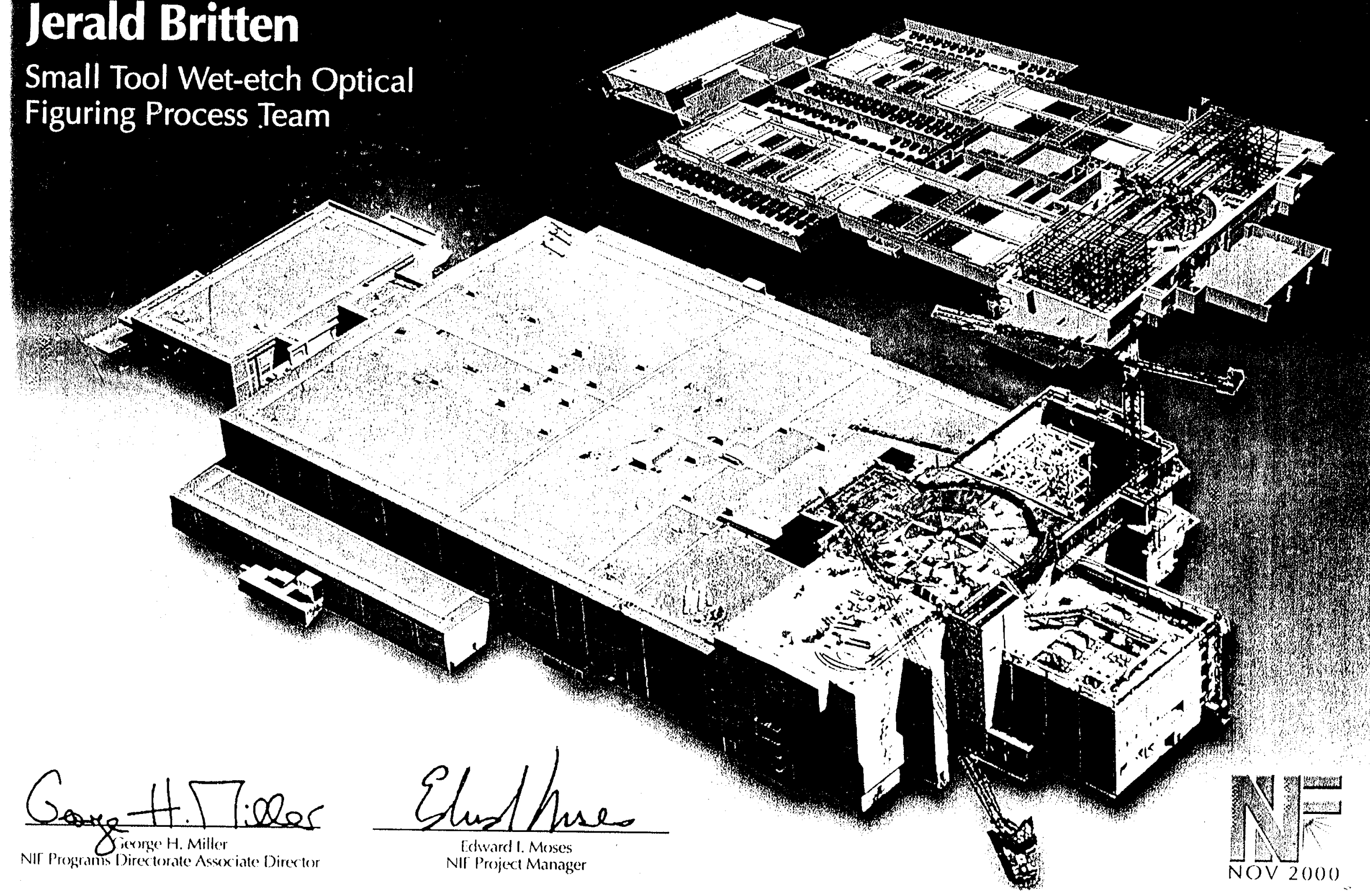